\title{
dosalgarves
}

\section{Opção SNC versus NIC: Empresas-mãe das entidades cotadas no mercado de ações de Lisboa}

\section{SNC versus IAS adoption: Parent companies listed on Euronext Lisbon}

\author{
Miguel Luzia \\ Universidade do Algarve, Faro, Portugal \\ mgluzia@gmail \\ Joaquim Sant'Ana Fernandes \\ Universidade do Algarve, Faro, Portugal \\ jsfer@ualg.pt \\ Cristina Gonçalves \\ Universidade do Algarve, Faro, Portugal \\ cjesus@ualg.pt
}

\begin{abstract}
Resumo
As entidades com valores cotados em bolsa da União Europeia estão obrigadas a adotar as Normas Internacionais de Contabilidade (NIC) nas contas consolidadas. Todavia, no que se refere às contas individuais das empresas incluídas nos perímetros de consolidação, coube a cada Estado-membro obrigar ou permitir a sua utilização. A opção nacional foi permitir a utilização do sistema de contabilidade português: Sistema de Normalização Contabilística (SNC). Neste estudo analisam-se os fatores que potencialmente explicam a opção pelas NIC nas entidades com valores cotados na Euronext Lisbon, no período 2005-2012. As variáveis explicativas foram agrupadas em fatores: ambiental, interno e relativos à administração, tendo-se apurado, através de um modelo logit, uma relação estatisticamente significativa para o setor de actividade, cotada em diversos mercados e inclusão no PSI-20 (fatores ambientais), o auditor, payout ratio, $b$-value (fatores internos) e remuneração fixa da administração. Os resultados suportam a premissa de que a decisão sobre a opção do modelo contabilístico resulta de um conjunto variado de fatores.
\end{abstract}

Palavras-chave: regulamento (CE) n. ${ }^{\circ}$ 1606/2002; contas individuais; opção NIC; SNC; Euronext Lisbon.

\begin{abstract}
Entities with securities listed on a stock exchange in the EU are obliged to adopt the International Accounting Standards (IAS) in their consolidated accounts. However, as for the individual accounts of the companies included in the parameters of consolidation of these entities, it would be up to each Member State to enforce or allow its use. The Portuguese option was to allow the utilization of the Portuguese accounting system: Sistema de Normalização Contabilística (SNC). This study analysis the factors that potentially explain the choice for the IAS by entities with securities listed on Euronext Lisbon, in the period 2005-2012. The explanatory variables were grouped into 3 sectors: environmental, internal and CEO profile, these being determined through a logit model, a statistically significant relationship to the sector of activity, listed in several markets and included in the PSI-20 (environmental factors), the auditor, payout ratio, b-value (internal factors) and fixed remuneration of management. The results support the premise that the decision on the choice of accounting model is a result of several factors.
\end{abstract}

Keywords: regulation (EC) no. 1606/2002; individual accounts; IAS option; SNC; Euronext Lisbon.

Dos Algarves: A Multidisciplinary e-Journal, 28 - 2016.

ISBN 2182-5580 ๑ ESGHT-University of the Algarve, Portugal.

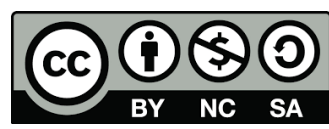

To cite this article: Luzia, M., Fernandes, J.S. \& Gonçalves, C. (2016). Opção SNC versus NIC: Empresas-mãe das entidades cotadas no mercado de ações de Lisboa. Dos Algarves: A Multidisciplinary e-Journal, 28, 68-86. doi: 10.18089/DAMeJ.2016.28.5 


\section{Introdução}

O Regulamento (CE) n. ${ }^{\circ}$ 1606/2002 (Parlamento Europeu e Conselho da União Europeia, 2002) obriga as entidades com valores cotados (adiante designadas por entidades cotadas) em bolsa da União Europeia (UE) a adotarem as Normas Internacionais de Contabilidade (NIC), na preparação e apresentação das Demonstrações Financeiras (DF) consolidadas, desde 2005. No entanto, no que se refere às DF individuais, das empresas incluídas nos perímetros de consolidação destas entidades, cabe a cada Estado-membro obrigar ou permitir a sua utilização. A opção portuguesa é permitir.

Considera-se que a opção entre utilizar as NIC ou as normas nacionais não é indiferente no que concerne à quantidade e qualidade da informação divulgada. As entidades que promovam políticas de mais e melhor informação optam pelas NIC, independentemente de Ihes estar associado eventualmente custos de contexto superiores. A opção pelas normas nacionais, nas contas individuais, pode também revelar uma subvalorização das contas individuais, admitindo-se que estas entidades consideram como suficiente a informação contida nas suas contas consolidadas, estas sim elaboradas obrigatoriamente em NIC.

As razões que subjazem à escolha deste estudo erradicam, por um lado, nas conclusões de diferentes investigações sobre o impacto da transição, que evidenciam alterações na posição financeira no balanço de abertura, preparado e apresentado de acordo com as NIC (Araújo, 2010; Horton \& Serafeim, 2010; Hung \& Subramanyam, 2007; Perramon \& Amat, 2006), isto é, a sua aplicação não é neutra, provoca alterações na posição financeira das entidades e, por outro, ao exposto na teoria no que concerne à divulgação da informação contabilística, que enfatiza a racionalidade económica das escolhas da gestão.

Neste contexto, constituiu-se como objetivo perceber que fatores potencialmente explicam a opção exercida pelas entidades, no que concerne às contas individuais das entidades que integram o perímetro de consolidação de uma entidade cotada. $O$ objeto de análise foram as entidades cotadas na Euronext Lisbon, no período 2005 a 2012.

A hipótese geral de investigação considera que as tomadas de decisão das entidades, ao mais alto nível, são o resultado de um conjunto complexo de fatores, dificilmente considerados na sua totalidade num modelo econométrico de análise.

$\mathrm{Na}$ hipótese de investigação considera-se três fatores, que incorporam as diversas perspetivas teóricas, tidos como relevantes na opção do referencial contabilístico:

- Fator ambiental que integra variáveis estruturais de enquadramento das entidades;

- Fator interno que integra aspetos intrínsecos das entidades;

- Fator administração que incorpora variáveis relativas ao Chief Executive Officer (CEO).

Este estudo contribui para a investigação sobre a opção pelas NIC das entidades portuguesas, dado que os estudos existentes são reduzidos e relativos a objetos diferentes: Guerreiro, Rodrigues e Craig (2012) sobre entidades sem títulos a cotação e Gonçalves e Fernandes (2011) que apenas analisam as entidades que integram o Portuguese Stock Index 20 (PSI-20). 


\section{Enquadramento teórico}

Sá (2002) e Borges, Rodrigues e Rodrigues (2010) definem a contabilidade como um sistema de informação onde existe um interface entre a fonte de informação, a organização e os utilizadores dessa informação. Tal consideração, entende-se à luz de um conjunto de teorias e estudos, que procuram explicar as razões que levam as empresas a divulgar um conjunto de informações múltiplas e heterogéneas.

Diversas teorias procuram explicar as razões subjacentes à quantidade e qualidade da informação voluntária (económico/financeira, social, ambiental, etc.) divulgada pelas entidades. Estas teorias relevam determinadas ênfases tais como a assimetria de informação entre agentes (Akerlof, 1970), a cedência de informação com o objetivo de sinalização (Spence, 1973), o papel da informação nas relações de agência (Jensen \& Meckling, 1976), a influência dos shareholders (Friedman, 1977) e dos stakeholders (Freeman \& McVea, 2001), o papel do ambiente nas opções empresariais (Meyer \& Rowan, 1977), a preocupação das entidades em adotar comportamentos que sejam aceites como legítimos (Suchman, 1995) e a gestão da informação voluntária como recurso de impacto económico (Healy \& Palepu, 2001).

Diversos estudos (Argenti, 1997; Campbell, 1997; Dumontier \& Raffournier, 1998; Eisenhardt, 1988; Watts \& Zimmerman, 1978) suportam e confirmam as contribuições teóricas destes investigadores, que apontam o nível de divulgação dependente de um conjunto de fatores que dão ênfase à racionalidade económica das escolhas de gestão e, nesse sentido, a informação poderá ser mais ou menos casuística. A quantidade e qualidade de informação divulgada voluntariamente, assim como o meio de divulgação utilizado, pode ser um sinal do estado financeiro e da estratégia de uma empresa: “[... ] as empresas com melhor desempenho (alta qualidade) utilizarão a internet para divulgar informação sobre a empresa, designadamente informação sobre o seu desempenho, enquanto empresas com baixo desempenho (baixa qualidade) tenderão a restringir o acesso desse tipo de informação aos seus acionistas" (Fernandes, 2008: 73).

As NIC obrigam a um nível de divulgação económico/financeira mais exigente e nesse sentido diversos estudos procuram identificar os fatores que condicionam a sua adoção.

Jensen e Meckling (1976), Watts e Zimmerman (1990), Chalmers e Godfrey (2004) e Gandía Cabedo e Andrés Pérez (2005) concluíram que a dimensão das firmas de auditoria ${ }^{1}$ tem um impacto significativo na escolha do normativo NIC, dado que as Big Four detêm recursos humanos e metodologias adaptadas às NIC. Como estas empresas possuem uma reputação de grande qualidade e de independência, e pretendem mantê-la, impõem aos clientes elevados níveis de divulgação.

Watts e Zimmerman (1990) defendem que os custos políticos estão relacionados com os diferentes setores de atividade e com a dimensão. Assim, o facto de pertencer a um determinado setor conduz à adoção de práticas de divulgação que as empresas entendem ser as mais adequadas para as especificidades desse setor.

Cooke (1989) indica que as empresas que operam no espaço internacional tendem a possuir melhores sistemas de gestão devido à complexidade das suas operações, pelo que têm necessidade de avaliar as alterações implícitas no processo de transição para as NIC e consequentemente divulgaram com maior facilidade informação nesse âmbito.

\footnotetext{
${ }^{1}$ As denominadas Big Four (Deloitte, PWC, KPMG e Ernst \& Young) detêm uma parcela muito significativa desta área de negócio.
} 
O estudo de Guerreiro, Rodrigues e Craig (2012) teve por objetivo explicar as razões da adoção voluntária pelas NIC, nas maiores empresas não cotadas portuguesas. Selecionaram uma amostra de 474 empresas e concluíram que a adoção das NIC é um caminho para aumentar o prestígio e demonstrar aptidão social. Também concluíram que subsidiárias das multinacionais são mais propensas a adotar as NIC de forma voluntária e que as empresas que adotam as normas nacionais têm uma maior autonomia na tomada de decisão organizacional.

Gonçalves e Fernandes (2011) analisaram a opção do enquadramento contabilístico no que concerne às contas individuais das empresas que integram o PSI-20. O estudo teve por objetivo aferir se as entidades exerceram a opção pelo referencial NIC, no período de 2005 a 2010.

Para este estudo retiraram do relatório e contas de cada empresa a seguinte informação:

- Indicação do referencial contabilístico no que concerne às contas individuais;

- Dimensão das empresas-mãe (volume de negócios);

- Internacionalização (volume de negócios em mercados estrangeiros);

- Rendibilidade (rendibilidade das vendas/serviços);

- Serviços de auditoria (sociedade emitente da certificação legal de contas).

Para testar o poder explicativo das variáveis selecionadas adotaram um modelo de regressão logística cuja variável dependente (dummy) representa a opção entre adotar, ou não, as NIC. Também utilizaram instrumentos de estatística descritiva e testes estatísticos paramétricos e não paramétricos. Os testes não validaram nenhuma variável como potencialmente explicativa. No entanto, Gonçalves e Fernandes (2011) observaram que as entidades direcionadas para a exportação optaram maioritariamente pelo referencial contabilístico NIC. Nos resultados, os mesmos autores concluíram que as entidades que optaram pelas NIC foram em número muito reduzido, embora aumentasse gradualmente ao longo do período analisado. A baixa adesão, segundo os investigadores, prendeu-se com a legislação fiscal vigente à data, que colocava "intencionalmente um "travão" a esta opção". Assim, Gonçalves e Fernandes (2011: 53) concluíram que existe um comportamento oposto ao esperado inicialmente: "Na nossa opinião vale a pena, em estudos posteriores, perceber a razão pela qual estas entidades não optaram pelo referencial [...] [NIC] para as suas contas individuais quando obrigatoriamente têm de o utilizar para as contas consolidadas.".

Considerando as conclusões dos estudos referidos, as variáveis que influenciam a opção de preparar e apresentar as DF de acordo com as NIC são: internacionalização, tipo de auditor, setor de atividade, dimensão.

\section{Objetivo e hipóteses do estudo}

Como se inferiu, pelos pressupostos subjacentes às diversas teorias que fundamentam as opções quanto à disponibilização da informação (teoria da agência, dos stakeholders, teoria institucional, entre outras) e pelos estudos referenciados, são diversos os fatores que podem ser invocados como explicativos das decisões das administrações. Este estudo 
procurou integrar estes fatores com outros, de natureza semelhante, de modo a conhecer as variáveis que ponderam na opção pelas NIC, nas entidades-mãe de grupos que têm títulos cotados em bolsa.

Neste contexto estabeleceu-se como objetivos do presente estudo:

1. Identificar as entidades que exerceram a opção pelo referencial NIC no que concerne à preparação e apresentação das DF relativas às contas individuais;

2. Determinar os fatores que explicam a opção pelo referencial NIC;

3. Estabelecer o modelo funcional adequado (logit) que relacione a variável dependente e as independentes consideradas como relevantes.

Na hipótese de investigação são considerados três fatores que incorporam as diversas perspetivas teóricas e que são tidos como relevantes para essa tomada de decisão:

- Fator ambiental que integra variáveis estruturais de enquadramento das entidades tais como o setor e os mercados de capitais onde negoceiam os seus títulos;

- Fator interno que integra aspetos intrínsecos das entidades tais como a dimensão, política de dividendos, sociedade de auditoria e o grau de internacionalização;

- Fator administração que incorpora variáveis relativas ao CEO tais como a remuneração, formação e experiência.

Desta forma explicita-se a seguinte hipótese de investigação:

- As políticas de enquadramento contabilístico das contas individuais das entidadesmãe de grupos com títulos admitidos à negociação na Euronext Lisbon estão associadas a fatores de natureza ambiental, natureza interna e ao perfil do CEO.

\section{Metodologia}

\subsection{Universo e amostra}

O universo deste estudo corresponde às entidades cotadas no Euronext Lisbon que, à data de 31 de dezembro de 2012, totalizavam quarenta e nove entidades.

Deste universo excluiu-se sete entidades, que segundo a classificação do Industry Classification Benchmark (ICB) pertencem ao setor financeiro, logo sujeitas a enquadramento contabilístico próprio, a EDP Renováveis, que utiliza nas contas individuais, as normas contabilísticas espanholas e o Sporting Clube de Portugal - Futebol SAD que não apresenta toda a informação necessária. Deste modo a amostra é constituída por quarenta entidades (que corresponde a $82 \%$ do universo) e o período da amostra está compreendido entre 1 de janeiro de 2005 e 31 de dezembro de 2012.

\subsection{Recolha e tratamento de dados}

Os dados relevantes, para o período em análise, foram recolhidos dos Relatórios de Contas (Comissão do Mercados de Valores Mobiliários, 2013) Consideraram-se as contas 
consolidadas e não as contas da entidade-mãe por se admitir serem aquelas que melhor espelham a imagem pública do grupo (imagem corporativa).

Através do anexo, no ponto relativo às bases de apresentação das DF foi possível averiguar se as entidades exerceram a opção pelas NIC.

Os dados da amostra têm uma estrutura em painel, que permite analisar as alterações das variáveis no espaço e no tempo. Utilizou-se um modelo logit para dados em painel, estimado pelo software estatístico Data Analysis and Statistical Software (STATA V. 11).

\subsection{Variáveis (dependente e independentes)}

Enunciada a hipótese de investigação definiu-se as variáveis de natureza ambiental, natureza interna e relativas ao CEO que potencialmente explicam a variável dependente.

A escolha das variáveis independentes foi influenciada, quer pela teoria, quer pelos estudos empíricos anteriormente referenciados e por análises exploratórias que permitem fundamentar as opções.

\subsubsection{Variável dependente}

A variável dependente “Opção contabilística (Op_cont)" é uma variável dicotómica. A opção pelo normativo internacional (NIC) assume o valor um (1) e a opção pelo normativo nacional (POC/SNC) valor zero (0).

\subsubsection{Variáveis independentes}

As variáveis independentes são as variáveis potencialmente explicativas da hipótese delineada e foram agrupadas em fatores a que se associa natureza diversa.

4.3.2.1 Fatores internos: Consideram-se fatores internos as características das entidades que contribuem para a visibilidade externa e são fatores de avaliação pelos investidores. Inclui-se no modelo as seguintes variáveis de caráter interno:

- Valor contabilístico (b-value) de uma entidade sinaliza a robustez e dele deduz-se diversos rácios financeiros relevantes para a análise. A relação esperada é que empresas com maior património, proxy de dimensão, adotem políticas de divulgação de informação mais completa, o que aplicado ao tema em questão manifesta-se pela adoção das NIC. Variável numérica contínua de caráter exploratório. Sinal esperado (+);

- Payout ratio é um rácio obtido entre os dividendos e os resultados por ação, que evidencia a política de dividendos das entidades. Esta variável tem natureza exploratória e espera-se que entidades com políticas mais expansivas de dividendos tendam a ser mais prudentes na divulgação de informação. Nessa medida, espera-se uma relação negativa entre uma política expansiva de dividendos e uma opção contabilística que envolva maior divulgação de informação. Variável numérica contínua de caráter exploratório. Sinal esperado (-);

- Auditoria (audit) evidencia o auditor da entidade. Entende-se que as empresas multinacionais de auditoria, denominadas de Big Four, serão mais exigentes com as empresas-clientes no que diz respeito à divulgação completa de informação. 
Variável dummy $(0,1)$ onde um representa uma sociedade Big Four. Valor esperado (+) (Gandía Cabedo \& Andrés Pérez, 2005; Gonçalves \& Fernandes, 2011);

- Mercado Externo (Mercext) é relativo ao volume de negócios por segmentos geográficos, excluindo o segmento onde Portugal está incluído. Uma maior relação com mercados estrangeiros cria maior exposição pública e pode levar à criação de mecanismos que sirva as necessidades de informação dos vários stakeholders. Desta forma é esperada a utilização do normativo internacional como elemento complementar dessa internacionalização. Sinal esperado (+) (Cooke, 1989; Gonçalves \& Fernandes, 2011).

4-3.2.2 Fatores ambientais: São fatores ambientais os contextos em que as entidades se integram e que segundo a teoria institucional podem conduzir a comportamentos semelhantes para entidades que partilhem condições análogas (Eisenhardt, 1988). Elege-se como variáveis ambientais o setor de atividade e o mercado de capitais:

- Setor (sec_bens_trans) é uma variável dummy que agrupa as entidades em dois grupos, em função da sua atividade principal: bens transacionáveis (1) e não transacionáveis (0). A atividade principal resulta da classificação ICB. Esta variável pode indicar a tendência de um determinado conjunto de empresas face ao normativo "ideal” para esse setor. Sinal esperado (+/-) (Suchman, 1995; Watts \& Zimmerman, 1990).

Como variáveis de mercado de capitais considera-se o facto de as entidades integrarem o índice PSI-20 e o de serem cotadas em mais de um mercado:

- Portuguese Stock Index 20 (PSI-20), dummy que assume o valor dicotómico (0;1), sendo um (1) quando a entidade integra o PSI-20. Na linha dos argumentos anteriormente apresentados é esperado que estas entidades, dada a sua maior visibilidade tenham uma atitude mais liberal, que se concretiza em mais divulgação de informação. É uma variável exploratória. Sinal esperado (+);

- Cotada em diversos mercados (multi_cot), dummy que assume o valor dicotómico $(0 ; 1)$, sendo que é um (1) quando está cotada em mais do que um mercado e zero (0) se apenas é cotada no mercado nacional. À semelhança das entidades internacionalizadas espera-se que estas entidades sujeitas a um escrutínio mais diversificado e exigente, estejam mais disponíveis para gerir os custos políticos e de agência, divulgando informação que satisfaça as exigências dos diversos stakeholders. É variável exploratória. Sinal esperado (+).

4-3.2.3 Fatores relativos ao CEO: Recolheu-se algumas variáveis caraterizadoras do perfil do CEO (formação académica, instituição de formação, interesse no capital da entidade, experiência profissional e remuneração), contudo apenas a remuneração apresenta-se como variável estatisticamente significativa. A omissão das restantes variáveis testadas não influenciou o modelo geral:

- Remuneração fixa do CEO (remun_fixa), variável numérica contínua que traduz o valor fixo auferido, durante um determinado ano. Este fator tende a ser maior 
quando há um conjunto de pressupostos que são cumpridos, nomeadamente um melhor resultado por parte da empresa. Sinal esperado (+) (Eisenhardt, 1988).

\subsection{Especificação do modelo}

Atendendo à dicotomia da variável dependente e à continuidade das variáveis independentes, deve-se optar por um modelo de regressão multivariada, que nesta investigação corresponde ao modelo logit.

Segundo Pindyck e Rubinfeld (2004), o modelo logit define-se como um modelo econométrico de seleção qualitativa, uma vez que gera respostas de procedimentos qualitativos do tipo presença ou ausência de um determinado atributo.

Os dados em painel podem fornecer dois tipos de modelos estatísticos: o modelo de efeitos fixos e o modelo de efeitos aleatórios. No modelo de efeitos fixos, as variáveis variam no espaço mas permanecem constantes ao longo do tempo. Nesse caso, não há efeitos temporais influenciando a regressão, mas apenas individuais (Baltagi, 2013/1995).

No modelo de efeitos aleatórios, os estimadores captam o efeito aleatório individual não observável e o efeito do tempo. Face a esta situação delineou-se um modelo de análise que seja o ponto de partida para os testes estatísticos:

(1) Op $_{\text {cont }_{i t}}=\beta_{0}+\beta_{1}$ sector $_{i t 1}+\beta_{2}$ multi_cot $_{i t 2}+\beta_{3}$ psi 20 $_{i t 3}+\beta_{4}$ audit $_{i t 4}+\beta_{5}$ payratio $_{i t 5}$ $+\beta_{6}$ Remun $_{\text {fixa }_{i t 6}}+\beta_{7}$ bvalue $_{i t 7}+\beta_{8}$ mercext $_{i t 8}+u_{i t}$

A existência de dois tipos de modelos estatísticos, de efeitos fixos e de efeitos aleatórios, torna imperativo averiguar a consistência dos dois modelos. Consequentemente utilizou-se o teste Hausman, que testa a ortogonalidade entre os efeitos aleatórios e regressores, e assim possibilita a escolha entre um ou outro modelo.

Para um teste Hausman $\left(\mathrm{chi}^{2}(6)=3.92 ; p\right.$-value $\left.=0.6876\right)$ constata-se que o modelo de efeitos aleatórios é o modelo mais adequado, dado que a hipótese nula de ortogonalidade dos efeitos individuais não pode ser rejeitada.

\section{Resultados}

\subsection{Caracterização da amostra}

Conforme se referiu, através do anexo, foi possível averiguar se as entidades exerceram a opção pelas NIC. Em 2012, 65\% das entidades adotaram as NIC, fruto de um aumento progressivo, mas com um incremento significativo em 2010 (mais seis entidades).

Este acréscimo pode ser justificado pela entrada em vigor do Sistema de Normalização Contabilística (SNC) cuja implementação acarretaria encargos significativos. Face à necessidade de incorrer em custos de transição de normativo admite-se que a opção pelas NIC não significaria um acréscimo significativo desses encargos. Por outro lado, tal pode dever-se à hipótese defendida por Gonçalves e Fernandes (2011), que o "travão" fiscal poderia estar a condicionar a opção pelas NIC. 


\subsubsection{Características qualitativas}

5.1.1.1 PSI-20: A amostra integra catorze entidades do PSI-20. O PSI-20 é o principal índice da Euronext Lisbon, ou seja, é o índice de referência do mercado de capitais português. Este índice é composto pelas ações das vinte maiores entidades cotadas na Euronext Lisbon. $\mathrm{O}$ Gráfico 1 evidencia a opção das entidades que integram e não integram o PSI-20 pelas NIC.

Gráfico 1. Adoção do normativo NIC

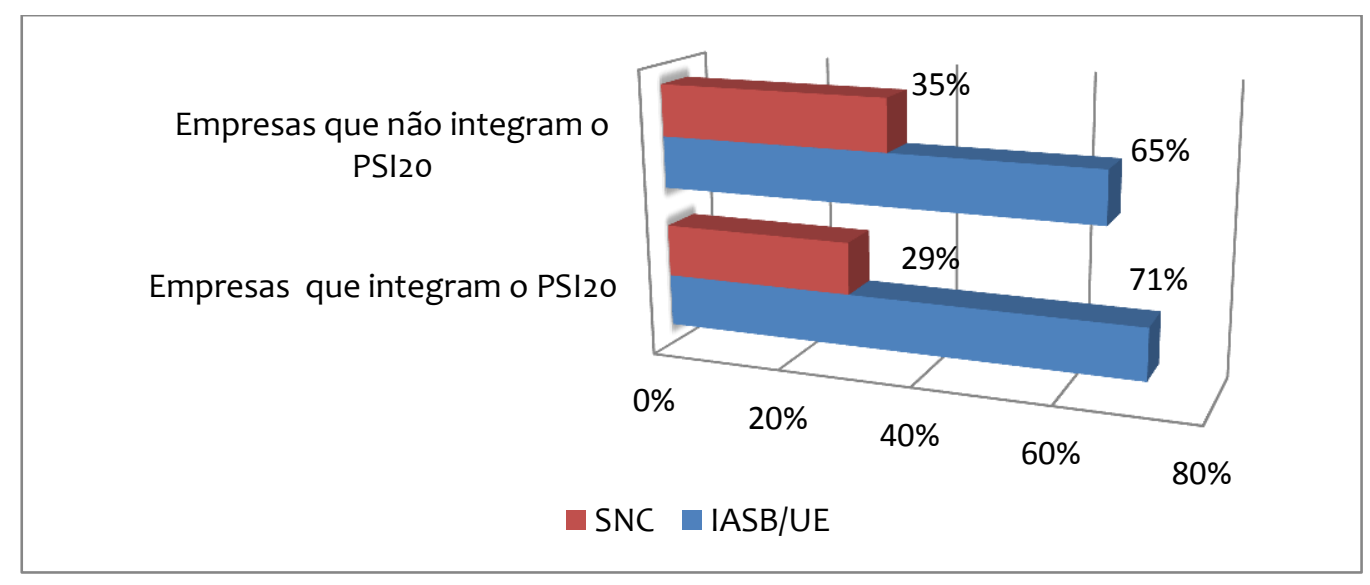

Fonte: Elaboração própria.

Uma análise da relação estatística (teste qui-quadrado) entre a independência entre pertencer ao PSI-20 e a opção pelo normativo NIC não revelou uma relação significativa ( $\chi 2$ $=2,496, p$-value $=0,114)$.

5.1.1.2 Cotadas em diversos mercados: Diversas entidades da amostra, muito possivelmente por opções de estratégia financeira, optaram por estar cotadas em diversos mercados de vários países. Esta escolha permite aproximar-se de mercados mais atrativos e atrair novos shareholders.

$\mathrm{Na}$ amostra em análise, $58 \%$ das entidades estão cotadas noutros mercados. Como é possível verificar na Tabela 1, as empresas que têm valores cotados em diversos mercados optaram maioritariamente pelo normativo internacional.

Tabela 1. Opção contabilística das entidades com títulos cotados em diversos mercados

\begin{tabular}{|l|l|c|}
\hline Cotada em diversos mercados & \multicolumn{2}{|c|}{ Normativo que adotou } \\
\hline \multirow{2}{*}{ Sim -23 Entidades } & POC/SNC - 5 Entidades & $22 \%$ \\
\cline { 2 - 3 } & NIC -18 Entidades & $78 \%$ \\
\hline \multirow{2}{*}{ Não -17 Entidades } & POC/SNC - 8 Entidades & $47 \%$ \\
\cline { 2 - 3 } & NIC -9 Entidades & $53 \%$ \\
\hline
\end{tabular}

Fonte: Elaboração própria.

Constata-se que as entidades cotadas em diversos mercados tendem a adotar as NIC com a intenção de responder às necessidades dos diversos stakeholders dos distintos mercados onde estão cotadas. Analisada a independência entre as duas variáveis confirmase existir uma relação significativa $\left(\chi^{2}=22,785, p\right.$-value $\left.<0,001\right)$. A intensidade desta 
associação testada pela estatística $V$ de Cramer que, apesar de significativa ( $p$-value < $0,001)$, é fraca $(0,273)$.

5.1.1.3 Setor: As entidades repartem-se por diversos setores de atividade, predominando o dos bens industriais e o dos serviços ao consumidor (no conjunto totalizam 57,5\% da amostra). Há setores que têm uma presença residual como o do petróleo e gás, que apenas é representado por uma entidade.

Para efeitos de análise os setores foram agrupados quanto à natureza dominante da sua atividade, relacionada com a produção de bens transacionáveis ou não transacionáveis. A Tabela 2 apresenta o agrupamento dos setores e a adoção das NIC em cada um deles:

Tabela 2. Opção das NIC por setor

\begin{tabular}{|cccc|}
\hline Setores & $\mathbf{N}^{\circ}$ entidades & NIC & \% adoção \\
\hline Bens não transacionáveis & 21 & 15 & $71 \%$ \\
\hline Bens transacionáveis & 19 & 12 & $63 \%$ \\
\hline
\end{tabular}

Fonte: Elaboração própria.

Analisada a independência entre as duas variáveis confirma-se existir uma relação significativa entre o setor e a adoção das NIC ( $\chi^{2}=50,065, p$-value < 0,001). A intensidade moderada (0.405) desta associação verifica-se através do teste estatístico $V$ de Cramer ( $p$ value $<0,001)$.

5.1.1.4 Auditoria: No que se refere a esta variável, constata-se que 70\% (vinte e oito entidades) das empresas da amostra são certificadas por uma das Big Four, o que indica que as empresas cotadas em bolsa tendem preferencialmente a certificarem as contas pelas empresas de auditoria com experiência multinacional, como se verifica na Gráfico 2.

Gráfico 2. Certificação legal de contas pelas Big Four

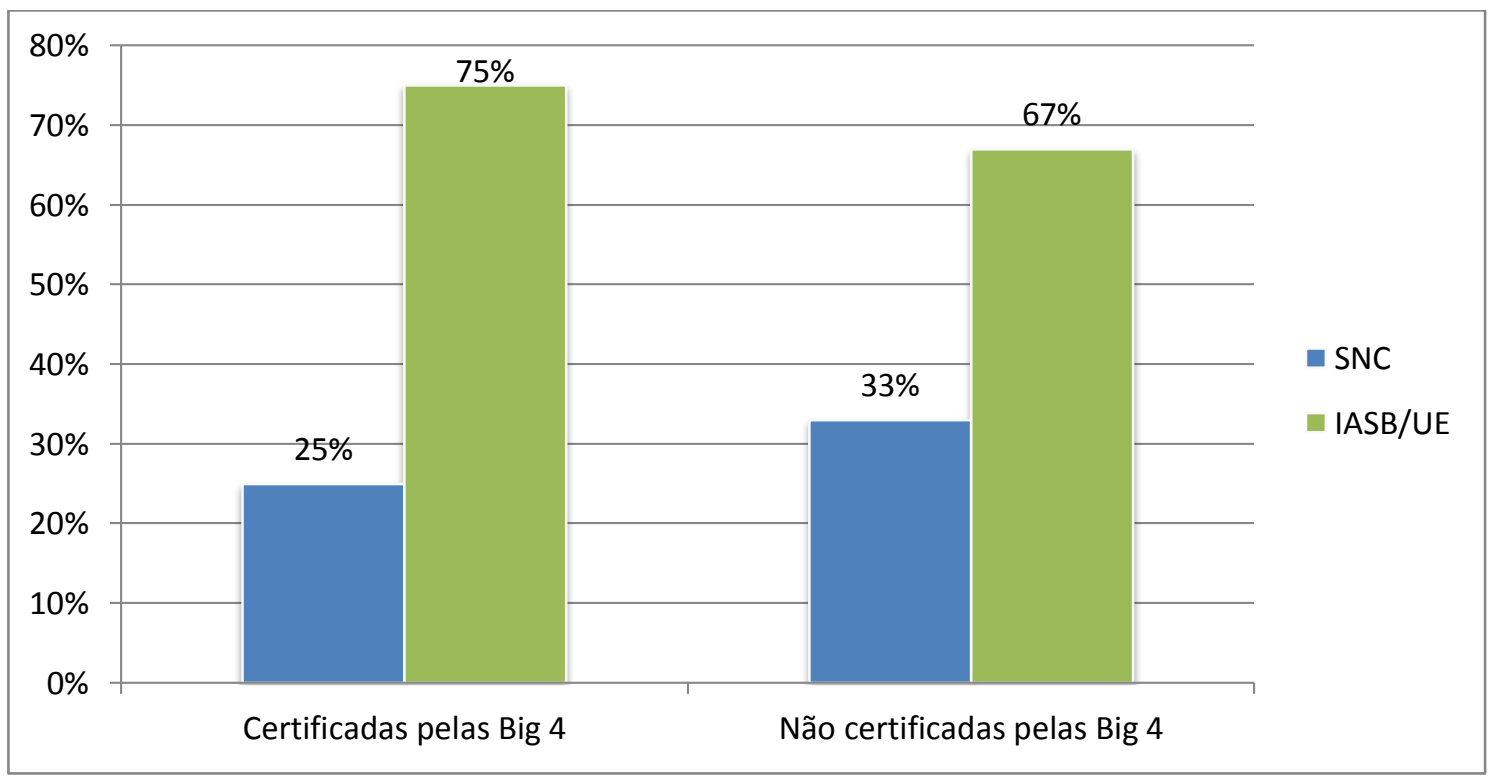

Fonte: Elaboração própria. 
Verifica-se que as empresas que são certificadas pelas Big Four tendem a adotar as NIC, o que vai ao encontro da análise esperada. Analisada a independência entre as duas variáveis confirma-se existir uma relação significativa entre a opção pelas NIC e estar certificada por uma Big Four ( $\chi_{2}=26,763, p$-value $\left.<0,001\right)$. A intensidade desta associação testada pela estatística $V$ de Cramer, apesar de significativa ( $p$-value $<0,001)$, é fraca $(0,297)$.

\subsubsection{Características quantitativas}

Analisou-se diversas variáveis quantitativas sobre as quais se apresenta uma breve análise. No sentido de determinar quais as estatísticas adequadas para determinar aquela relação, testou-se a normalidade da distribuição das variáveis (teste Kolmogorov - Sminorv) constatando-se, para um nível de significância de 5\%, poder rejeitar a hipótese de normalidade da distribuição. Contudo, apesar de não se confirmar a distribuição normal das variáveis e considerando a amostra como de grande dimensão $(n>30)$, optou-se por utilizar o teste $t$ de student para diferenças de médias entre as subamostras. Na leitura da estatística considerou-se se as amostras tinham ou não variâncias homogéneas (teste Levene). A Tabela 3 indica as estatísticas descritivas referentes às características quantitativas.

Tabela 3. Estatísticas descritivas

\begin{tabular}{|l|r|r|r|r|r|}
\cline { 2 - 6 } & \multicolumn{1}{c|}{ N } & \multicolumn{1}{c|}{ Mean } & \multicolumn{1}{c|}{ Minimum } & \multicolumn{1}{c|}{ Maximum } & \multicolumn{1}{c|}{ Std. Deviation } \\
\hline Merc. Ext $\left(\mathbf{1 0}^{\mathbf{6}} \boldsymbol{\epsilon}\right)$ & 305 & 655,8332 & 0,00 & 7884,48 & 1267,40126 \\
\hline B-value $\left(\mathbf{1 0}^{\mathbf{6}} \boldsymbol{\epsilon}\right)$ & 305 & 2,3002 & $-1,26$ & 15,54 & 2,50212 \\
\hline Payratio & 305 &, 3427 & $-2,38$ & 11,66 &, 97765 \\
\hline Remun_fixa $\left(\mathbf{1 0}^{\mathbf{6}} \boldsymbol{\epsilon}\right)$ & 302 & 1,7172 &, 11 & 8,36 & 1,39191 \\
\hline
\end{tabular}

Fonte: Elaboração própria.

5.1.2.1 Mercado externo: Esta variável pretende determinar em que medida as entidades direcionam os negócios para o mercado externo. O mercado externo corresponde ao volume de negócios que uma empresa realiza com outros países. Considera-se que as empresas maioritariamente exportadoras têm que satisfazer as necessidades de um leque mais amplo de stakeholders, pelo que é necessário manter políticas adaptadas aos ambientes económicos onde operam, assim tendem a adotar normas com maiores níveis de divulgação.

Ao analisar a amostra, constatou-se que 33\% do volume de negócios das empresas corresponde à exportação. Treze entidades têm 50\% (ou mais) do volume de negócios dirigido à exportação, como se constata na tabela seguinte. 
Tabela 4. Entidades exportadoras e o normativo adotado

\begin{tabular}{|l|l|}
\hline \% do Mercado Externo no Volume Negócios & Normativo Utilizado \\
\hline $\begin{array}{l}\text { Empresa "Exportadora" - Mais de 50\% do volume de } \\
\text { negócios é exportado - 13 Entidades }\end{array}$ & SNC - 4 Entidades - 31\% \\
\cline { 2 - 2 } $\begin{array}{l}\text { Empresa não "Exportadora" - Menos de 50\% do volume de } \\
\text { negócios é exportado - 27 Entidades }\end{array}$ & SNC - 9 Entidades - 69\% \\
\cline { 2 - 2 } & NIC - 18 Entidades - 67\% \\
\hline
\end{tabular}

Fonte: Elaboração própria.

Analisada a relevância da natureza exportadora das entidades e a relação com a opção normativa contabilística constata-se haver uma relação estatisticamente significativa ( $t$ de student = -3,839; $p$-value < 0,001, amostras de variância não homogénea) entre estas duas variáveis, confirmando esta relação. Verifica-se que as empresas mais exportadoras tendem a optar pelas NIC.

5.1.2.2 Valor contabilístico (b-value): O valor contabilístico representa a diferença entre ativos e passivos totais (ou o valor contabilístico de uma ação). o b-value é também, para além do valor de mercado, um elemento de avaliação das entidades. Na Tabela 5 constatase as opções normativas das entidades, conforme se situam acima ou abaixo do valor médio contabilístico para amostra (Tabela 3).

Tabela 5. Valor contabilístico e o normativo adotado

\begin{tabular}{|l|l|c|}
\hline \multicolumn{1}{|c|}{ Valor Contabilístico } & \multicolumn{2}{|c|}{ Normativo que adotou } \\
\hline \multirow{2}{*}{ Acima da média - 13 entidades } & POC/SNC - 6 Entidades & $46 \%$ \\
\cline { 2 - 3 } & NIC - 7 Entidades & $54 \%$ \\
\hline $\begin{array}{l}\text { Abaixo da média - 27 } \\
\text { entidades }\end{array}$ & POC/SNC - 7 Entidades & $26 \%$ \\
\cline { 2 - 3 } & NIC - 20 Entidades & $74 \%$ \\
\hline
\end{tabular}

Fonte: Elaboração própria.

Constata-se que há uma tendência para as empresas adotarem o normativo nacional quando apresentam um $b$-value acima da média, confirmando-se na análise bivariada que este fator é estatisticamente significativo ( $t$ de student $=3.607 ; p$-value $<0,001$ para amostras de variâncias não homogéneas).

5.1.2.3 Payout ratio: O payout ratio corresponde à proporção que a empresa está disposta a pagar de dividendos em função dos resultados por ação, isto é, uma proporção muito baixa de pagamento indica que a empresa está focada principalmente na retenção dos lucros, em detrimento do pagamento de dividendos. 
Gráfico 3. Relação payout ratio com opção normativa

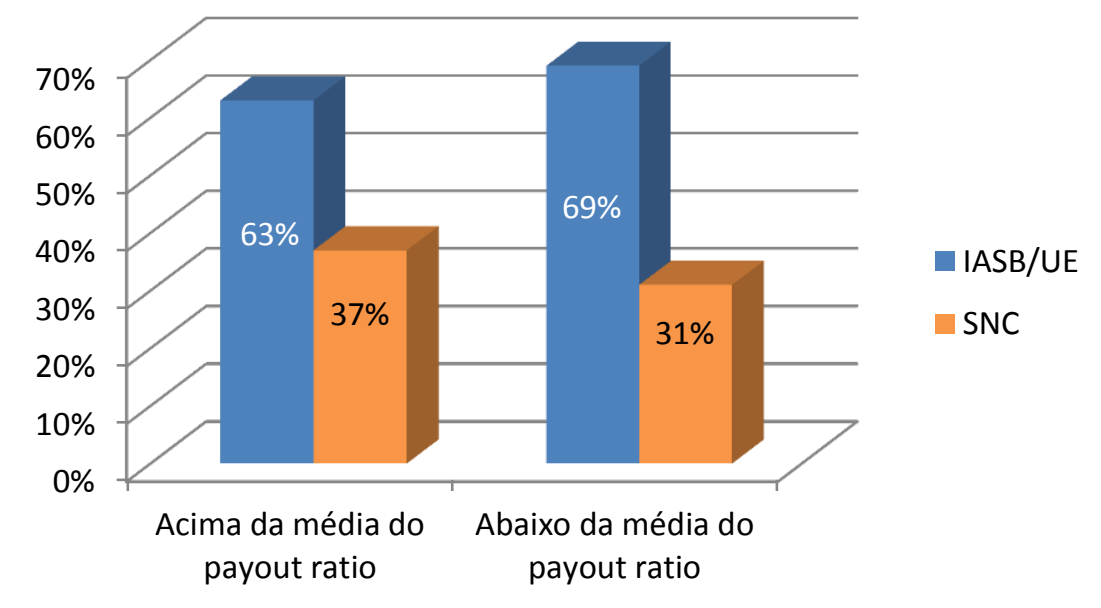

Fonte: Elaboração própria.

Através do Gráfico 3 é possível verificar que as entidades que apresentam um payout ratio acima da média (Tabela 3) tendem a adotar o normativo SNC contrariamente à opção das entidades que apresentam um payout ratio abaixo da média. Contudo este fator não explica a opção das entidades pelo normativo NIC ( $t$ de student $=0,1,570, p$-value $=0,119$ ).

5.1.2.4 Remuneração fixa do CEO: Assumindo a média calculada na Tabela 3, constata-se que $40 \%$ do CEO das entidades aufere um rendimento superior a essa média. O valor auferido poderá ser considerado um incentivo para práticas de gestão em consonância com os interesses dos acionistas em deter informação mais completa. Apresenta-se no Gráfico 4 a relação entre a remuneração fixa auferida e o tipo de normativo adotado.

Gráfico 4. Remuneração fixa auferida e o tipo de normativo adotado

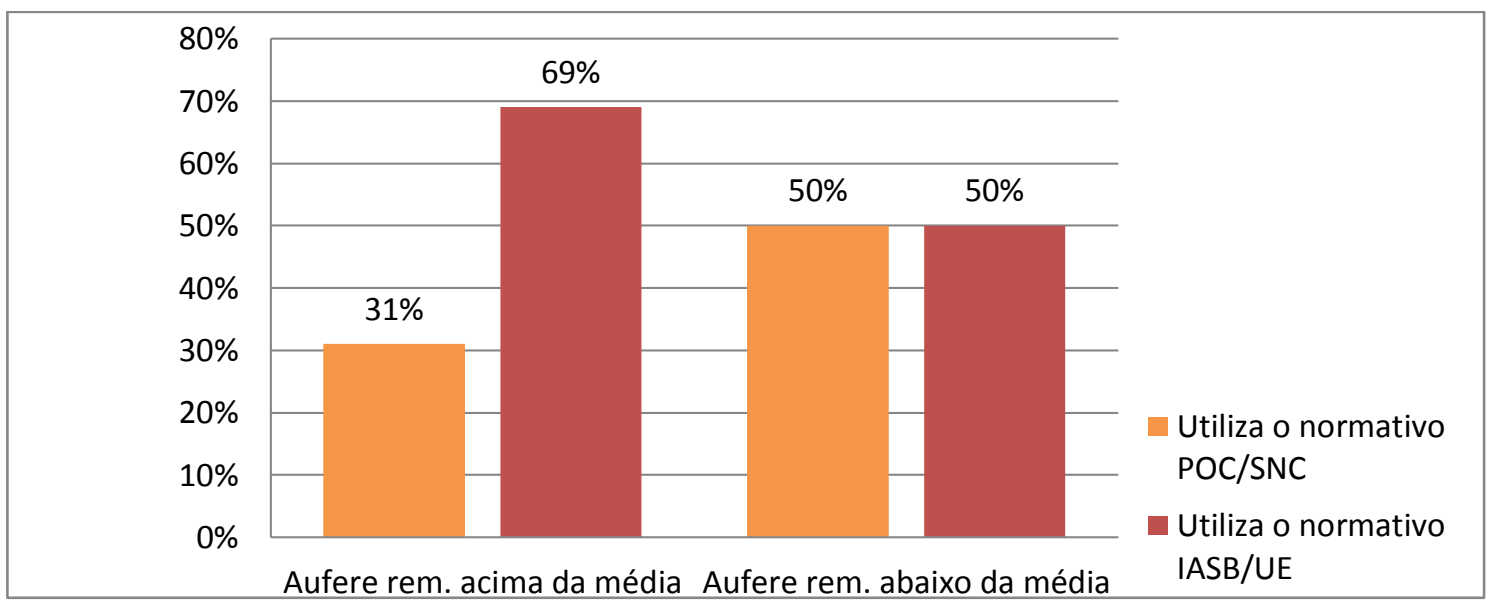

Fonte. Elaboração própria.

Confirma-se que os administradores com remunerações mais altas gerem empresas que optam maioritariamente pelas NIC. Essa relação tem confirmação estatística (t student = -2,484; $p$-value < 0,05 para variâncias homogéneas). 
5.1.3 Análise do modelo com dados em painel

O modelo logit ou modelo de regressão logística exprime-se através de um conjunto de variáveis contínuas, num determinado período e representa uma determinada resposta com duas determinações possíveis. No modelo delineado, testou-se um conjunto de fatores de natureza ambiental, natureza interna e relativos ao CEO. O modelo logit para dados em painel e efeitos aleatórios, apresentou um bom ajustamento global (teste de Wald ou likelihood-ratio teste $\left(\chi_{2}^{2}=26,28 ; p\right.$-value < 0,05). O resultado do modelo logit é demonstrado na Tabela 6 .

Tabela 6. Resultado do modelo logit com dados em painel

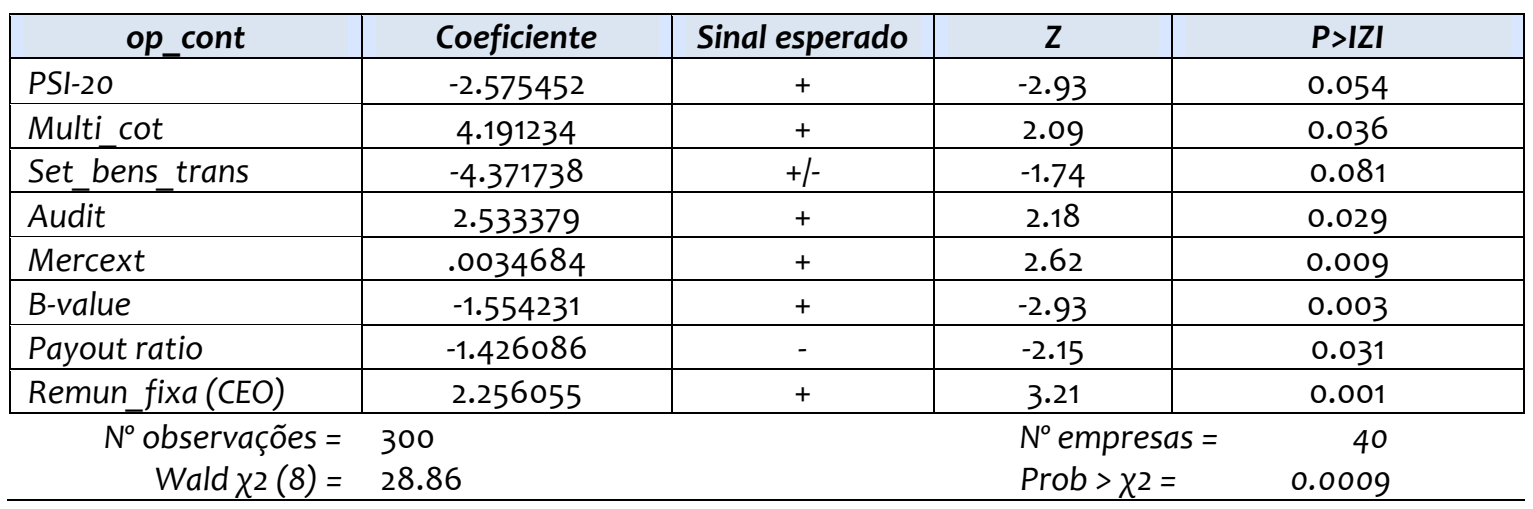

Fonte: Elaboração própria.

Constata-se que os vários fatores explicam o modelo para um nível de significância de $5 \%$. Considerando um nível de significância menos exigente ( $p$-value $<0,1)$ todas as variáveis têm algum tipo de relação com a variável independente.

Pode-se deduzir que os fatores enunciados na hipótese influenciam a decisão da gestão quanto à opção do enquadramento contabilístico (NIC versus SNC).

Quanto ao fator ambiental verifica-se que o setor e o mercado de capitais são variáveis explicativas. Confirma-se à luz da teoria institucional que o ambiente organizacional onde a empresa está inserida leva a adotar as práticas e procedimentos condizentes com esse meio.

Empresas do mesmo setor estão em regra, sujeitas ao mesmo tipo de regulamentação, subordinam-se às mesmas contingências e disputam mercados. É natural que muitos dos seus comportamentos sejam semelhantes, pautados pelos comportamentos das empresas líderes. De acordo com Watts e Zimmerman (1990), empresas do mesmo setor tendem a adotar práticas de divulgação que entendem ser as mais adequadas para a especificação desse setor. Constata-se neste caso que é menor a probabilidade das empresas do setor de bens transacionáveis, comparativamente com as dos bens não transacionáveis, de optarem pelas NIC. Estes resultados são confirmados pela adoção significativa das empresas de setor de bens não transacionáveis (71\%) contra apenas 53\% das restantes.

As empresas que submetem títulos à negociação em mais do que uma bolsa de valores apresentam uma probabilidade maior de optar pelas NIC. Esta relação também pode explicar-se à luz da teoria dos stakeholders. O facto das empresas com valores cotados em diversos mercados ou desenvolverem negócios em vários mercados, cria uma exposição pública mais abrangente e eventualmente mais exigente, pelo que a cedência de 
informação de natureza facultativa e/ou obrigatória pode ser uma estratégia de minimização de conflitos que prejudiquem o desempenho nesses mercados.

O PSI-20 relaciona-se de forma negativa com a opção pelas NIC, isto é, as empresas deste índice têm menor probabilidade de adotarem estas normas do que adotar o normativo nacional, resultado contrário ao esperado. A relação esperada era diferente porque associava-se estas empresas a níveis de visibilidade semelhante aos do grupo anterior (multicotadas). Avança-se como possível explicação o facto do mercado de capitais português não ter um nível de exigência em termos de informação que exceda aquela que é divulgada pelo grupo nas contas consolidadas, não pressionando a empresa-mãe a ter políticas de divulgação mais exigentes nas contas individuais.

Quanto ao fator interno também se confirma a existência de variáveis explicativas da opção, duas influenciando negativamente (valor contabilístico e payout ratio) e duas influenciando positivamente: o auditor e o mercado externo.

O valor contabilístico ( $b$-value) relaciona-se negativamente com a opção contabilística, também com um sinal contrário ao esperado. Esta relação poderá ser explicada pela preferência das entidades por políticas contabilísticas mais conservadoras que deem mais confiança aos investidores. Apesar do SNC não divergir substancialmente das NIC, este é mais simples, com menos opções e portanto mais compreensível para os investidores. Também se pode aduzir a justificação do papel subsidiário das contas individuais da empresa-mãe, face às suas contas consolidadas, que reflete todo o conjunto de entidades do grupo.

O payout ratio é um indicador que também está relacionado negativamente com a adoção das NIC. A distribuição de dividendos poderá ser vista como uma diminuição das expectativas de crescimento das entidades pela diminuição da capacidade de autofinanciamento, o que pode justificar algumas estratégias de comunicação mais orientadas para o curto-prazo. Esse efeito de uma política de distribuição de dividendos pode resultar na "obrigação moral" de manter essa política no futuro. A relação negativa entre a opção pelas NIC e o payout ratio poderá ser justificada pelas maiores exigências de divulgação de informação por parte deste normativo.

O tipo de auditoria é um fator que já foi abordado noutros estudos (Gonçalves \& Fernandes, 2011), onde se comprova a existência de influência das Big Four nas empresas que adotam o normativo NIC. Associa-se a estas empresas uma maior pressão para a utilização de um normativo mais completo e amplo. Autores como Jensen e Meckling (1976), Watts e Zimmerman (1990) e Gandía Cabedo e Andrés Pérez (2005) validaram essas conclusões justificando que as grandes firmas de auditoria possuíam recursos humanos e metodologias que permitem adoção das NIC, facilitando dessa forma o processo de transição.

O mercado externo pode ser visto numa dupla perspetiva de fator interno porque resulta de uma orientação comercial das entidades, mas também tem componente ambiental na medida que expõe a empresa a públicos diversos. Na linha do que foi referido para a reação das entidades aos desafios colocados com os mercados, quer de capitais, quer comerciais, elas tenderão a evitar más interpretações da informação, sujeitando-se a normas com maior credibilidade internacional, justificando assim as empresas exportadoras a optarem preferencialmente pelas NIC. Segundo Cooke (1989) as empresas que operam no espaço internacional tendem a possuir melhores sistemas de gestão devido à complexidade das operações, pelo que estão suficientemente preparadas para enfrentarem os desafios 
associados a uma transição para as NIC e mais dispostas a divulgar informação sobre as operações.

Em relação ao fator administração, a remuneração fixa relaciona-se positivamente com a opção NIC. Esta relação poderá ser explicada à luz da teoria de agência na medida em que uma maior remuneração dos administradores pode significar, quer um sinal de credibilidade e conhecimento do CEO, quer um maior nível de satisfação dos acionistas, por deterem informação mais completa e produzida com níveis de exigência superiores.

\section{Conclusão}

A crescente internacionalização das empresas levou à necessidade da criação de um normativo contabilístico internacional que fosse ao encontro das exigências dos mercados internacionais e, nesse sentido, o Parlamento Europeu e o Conselho da União Europeia (2002) publicam o Regulamento (CE) n. ${ }^{\circ}$ 1606/2002, que obrigou as entidades com valores admitidos em bolsa a apresentar as DF consolidadas de acordo com o normativo NIC. No entanto, as contas individuais destas entidades podem ser preparadas de acordo com as normas nacionais.

Este estudo teve como principal objetivo analisar os fatores que influenciam as entidades a adotar as NIC, nas contas individuais, no contexto das diversas teorias da informação.

Apesar das contas individuais das empresas-mãe estarem refletidas nas contas consolidadas, considerou-se pertinente a análise do enquadramento contabilístico das contas individuais destas empresas, porque se consideram igualmente importantes para os investidores por força do papel que estas têm na dinâmica do grupo, nas decisões estratégicas de investimento, financiamento e internacionalização, entre outros aspetos.

Este trabalho completa o estudo de Gonçalves e Fernandes (2011) dado que inclui todas as empresas cotadas no mercado de valores mobiliários de Lisboa, analisa um horizonte temporal maior e integra mais variáveis potencialmente explicativas. Encontrou-se algumas variáveis explicativas comuns: o auditor e o mercado externo.

Para estimar a relação entre a variável dependente (opção NIC) e as variáveis potencialmente explicativas, utilizou-se o modelo logit, no qual se obtiveram relações estatisticamente significativas entre a opção por enquadramento contabilístico e variáveis como o setor, cotada em diversos mercados, PSI-20, auditoria, payout ratio, $b$-value, remuneração fixa do CEO.

Releva-se neste trabalho a influência que a exposição externa das empresas tem nas opções contabilísticas. Encontrou-se consistência nos resultados associados à opção pelas NIC nas empresas com maior visibilidade externa, quer no mercado de negócios, quer no mercado de capitais. Diversas teorias suportam estes resultados, designadamente a institucional, da agência e dos stakeholders, atribuindo uma racionalidade económica às opções empresarias no sentido de encontrar soluções que permitam uma gestão mais adequada às expetativas dos grupos de pressão mais relevantes.

Também se confirma a tendência para que as entidades adotem comportamentos homogéneos à indústria à qual pertencem. Justifica-se este comportamento à luz das teorias, designadamente a teoria institucional, pelo mimetismo natural em relação a 
comportamentos das entidades líderes, considerados adequados em determinado contexto.

As firmas internacionais de auditoria também explicam a opção, eventualmente pelo papel facilitador que desempenham na implementação das NIC dado disporem de recursos adequados para essa função. É admissível que estas entidades também pressionem os clientes a adotarem as mesmas.

O papel do CEO é fundamental na decisão estratégica do enquadramento normativo, na medida em que a escolha tem uma forte componente qualitativa e de sinalização de rigor e transparência. Verifica-se relação positiva entre a remuneração do administrador e a opção pelas NIC facto que se interpreta de uma forma mais ampla do que essa relação bivariada. Apesar de uma maior remuneração associar-se a um percurso de sucesso reconhecido pelos acionistas, considera-se que o papel deste é fulcral na interpretação dos sinais externos e internos para a tomada decisão. Neste sentido interpreta-se esta variável como uma proxy da capacidade de decisão.

Três variáveis - PSI-20, payout ratio e b-value (valor contabilístico) - relacionam-se negativamente com a opção pelas NIC. Interpreta-se estes fatores como geradores de pressão para os quais a gestão quererá ter maior liberdade na administração da informação a ceder publicamente. Considera-se que as NIC apresentam um duplo acréscimo de exigência: são mais completas nas divulgações e estão sujeitas a um escrutínio internacional. Neste sentido, a utilização de normas nacionais poderá ser mais adequada aos interesses institucionais, na medida em que poderão permitir tornar privada informações que em contextos mais exigentes teriam natureza pública. Esta relação negativa também poderá espelhar uma subvalorização das contas individuais face às contas consolidadas.

As empresas que reconhecem vantagens nas NIC fazem-no em coerência com um conjunto de motivações designadamente como reforço da legitimidade e em consonância com as expectativas que recaem sobre ela.

As principais limitações imputáveis a este estudo são, por um lado, não terem sido auscultados os CEO das entidades, no sentido de averiguar as motivações para as escolhas normativas e, por outro, a não consideração de outras variáveis potencialmente explicativas, o que pode ser colmatado em investigação futura por inquérito à administração das empresas e introdução de novos fatores eventualmente explicativos.

\section{Referências bibliográficas}

Akerlof, G.A. (1970). The market for "lemons": Quality uncertainty and the market mechanism. The Quarterly Journal of Economics, 84 (3), 488-500. doi: 10.2307/1879431

Araúijo, S.M.A. de (2010). Impacto da aplicação das normas internacionais de contabilidade nas empresas do PSI20 (Dissertação de mestrado). Instituto Superior de Economia e Gestão, Lisboa.

Argenti, J. (1997). Stakeholders: The case against. Long Range Planning, 30 (3), 442-445. doi: 10.1016/S0024-6301(97)00004-6

Baltagi, B.H. (2013/1995). Econometric analysis of panel data. 5. edição. West Sussex: John Wiley \& Sons.

Borges, A., Rodrigues, A. \& Rodrigues, R. (2010). Elementos da contabilidade geral. 25. ${ }^{a}$ edição. Lisboa: Áreas Editora.

Campbell, A. (1997). Stakeholders: The case in favour. Long Range Planning, 30 (3), 446-449. doi: $10.1016 /$ S0024-6301(97)00003-4 
Chalmers, K. \& Godfrey, J.M. (2004). Reputation costs: The impetus for voluntary derivative financial instrument reporting. Accounting, Organizations and Society, 29 (2), 95-125. doi: 10.1016/S03613682(02)00034-X

Comissão do Mercados de Valores Mobiliários (2013). Relatórios de prestação de contas: Contas anuais. Lisboa: Sistema de Difusão de Informação. Disponível em http://web3.cmvm.pt/sdi/emitentes/

Cooke, T.E. (1989). Voluntary corporate disclosure by Swedish companies. Journal of International Financial Management \& Accounting, 1 (2), 171-195. doi: 10.1111/j.1467-646X.1989.tboooo9.X

Dumontier, P. \& Raffournier, B. (1998). Why firms comply voluntary with IAS: An empirical analysis with Swiss Data. Journal of International Financial Management \& Accounting, 9 (3), 216-245. doi: 10.1111/1467-646X.00038

Eisenhardt, K.M. (1988). Agency - and institutional - theory explanations: The case of retail sales compensation. Academy of Management Journal, 31 (3), 488-511. doi: 10.2307/256457

Fernandes, J.S. (2008). Información financiera en suporte electrónico: Un análisis de las empresas portuguesas (Tese de doutoramento). Universidade de Huelva, Huelva.

Freeman, R.E. \& McVea, J. (2001). A stakeholder approach to strategic management. (Working Paper N. ${ }^{\circ}$ 01-02). Boston, Darden Graduate School of Business Administration, University Virginia.

Friedman, M. (1977). Capitalismo e liberdade. Rio de Janeiro: Artenova.

Gandía Cabedo, J.L. \& Andrés Pérez, T. (2005). e-Gobierno corporativa y transparencia informativa en las sociedades cotizadas españolas: Un estudio empírico. Comisión Nacional del Mercado de Valores, Dirección de Estudios Y Estadísticas, Monografías N. ${ }^{\circ} 8$.

Gonçalves, C. \& Fernandes, J.S. (2011). As opções contabilísticas das entidades do PSI 20. Revista Contabilista/TOC, 132, 50-54.

Guerreiro, M.S., Rodrigues, L.L. \& Craig, R. (2012). Voluntary adoption of international financial reporting standards by large unlisted companies in Portugal - Institutional logics and strategic responses. Accounting, Organizations and Society, 37 (7), 482-499. doi: 10.1016/j.aos.2012.05.003

Healy, P.M. \& Palepu, K.G. (2001). Information asymmetry, corporate disclosure, and the capital markets: A review of the empirical disclosure literature. Journal of Accounting and Economics, 31 (1-3), 405-440. doi: 10.1016/S0165-4101(01)00018-0

Horton, J. \& Serafeim, G. (2010). Market reaction to and valuation of IFRS reconciliation adjustments: First evidence from the UK. Review of Accounting Studies, 15 (4), 725-751. doi: 10.1007/s11142009-9108-5

Hung, M. \& Subramanyam, K.R. (2007). Financial statement effects of adopting international accounting standards: The case of Germany. Review of Accounting Studies, 12 (4), 623-657. doi: 10.1007/s11142-007-9049-9

Jensen, M.C. \& Meckling, W.H. (1976). Theory of the firm: Managerial behavior, agency costs and ownership structure. Journal of Financial Economics, 3 (4), 305-360.

Meyer, J.W. \& Rowan, B. (1977). Institutionalized organizations: Formal structure as myth and ceremony. American Journal of Sociology, 83 (2), 340-363.

Parlamento Europeu e Conselho da União Europeia (2002, 19 julho). Regulamento (CE) N. ${ }^{\circ} 1606 / 2002$, relativo à aplicação das normas internacionais de contabilidade. Jornal Oficial, L 243 (11/09/2002), $0001-0004$.

Perramon, J. \& Amat, O. (2006). IFRS introduction and its effect on listed companies in Spain. (Working Paper). Barcelona, Faculty of Economic and Business Sciences, Universitat Pompeu Fabra.

Pindyck, R.S. \& Rubinfeld, D.L. (2004). Econometria: Modelos e previsões. São Paulo: Campus.

Sá, A.L. de (2002). Teoria da contabilidade. São Paulo: Atlas.

Spence, M. (1973). Job market signaling. The Quarterly Journal of Economics, 87 (3), 355-374.

Suchman, M.C. (1995). Managing legitimacy: Strategic and institutional approaches. Academy of Management Review, 20 (3), 571-610. doi: 10.5465/AMR.1995.9508080331

Watts, R.L. \& Zimmerman, J.L. (1978). Towards a positive theory of the determination of accounting standard. The Accounting Review, 53 (1), 112-134.

Watts, R.L. \& Zimmerman, J.L. (1990). Positive accounting theory: A ten year perspective. The Accounting Review, 65 (1), 131-156. 
Miguel LuzıA é licenciado em Economia e Mestre em Contabilidade pela Faculdade de Economia da Universidade do Algarve. É Contabilista Certificado desde 2015 e desempenha atualmente funções na Vilamoura Lusotur, S.A.. Em coautoria, apresentou comunicações em congressos internacionais de contabilidade. É autor de artigos de opinião de Contabilidade e Fiscalidade para o jornal eletrónico Sul Informação. Endereço institucional: Escola Superior de Gestão, Hotelaria e Turismo da Universidade do Algarve, Campus da Penha, Estrada da Penha, 8005-139 Faro, Portugal.

JoAquim SANT'ANA FeRnandes é professor adjunto da Escola Superior de Gestão, Hotelaria e Turismo da Universidade do Algarve onde leciona unidades curriculares na área da contabilidade, em cursos de licenciatura e mestrado. É coautor dos livros Relato Financeiro: Interpretação e Análise e Contabilidade Financeira Explicada: Manual Prático. Tem lecionado em diversas ações de formação dirigidas a profissionais de contabilidade e tem coordenado diversos estudos económicos. Endereço institucional: Escola Superior de Gestão, Hotelaria e Turismo da Universidade do Algarve, Campus da Penha, Estrada da Penha, 8005-139 Faro, Portugal.

CRIStina GonçAlves é professora adjunta da Escola Superior de Gestão, Hotelaria e Turismo da Universidade do Algarve onde leciona desde 1992. Tem ministrado diversas disciplinas na área da Contabilidade, em curso de licenciatura e de mestrado, nomeadamente Contabilidade Financeira Avançada e Ética Empresarial e Deontologia Profissional. É coautora de diversos livros sobre contabilidade e ética profissional. É convidada regularmente para ministrar cursos de formação. Endereço institucional: Escola Superior de Gestão, Hotelaria e Turismo da Universidade do Algarve, Campus da Penha, Estrada da Penha, 8005-139 Faro, Portugal.

Submetido em 20 março 2014

Aceite em 3 junho 2015 